\title{
FUNDAMENTALS OF THERMAL POWER GENERATION
}

\author{
Mohammed Elamin \\ Department of Mechanical and Aerospace Engineering, North Carolina State University, \\ Raleigh, NC 27695, United States
}

\begin{abstract}
This review article discusses the different aspects of thermal power generation including plant components, engine types and the fundamental of thermodynamics with respect to power generation. The main components of thermal power plants and their role in the operation of the power plant are discussed. Understanding the main concepts of Rankine cycle, thermodynamics, and heat transfer laws is vital in power generation engineering. The second part of this review article investigated the Rankine cycle process, heat transfer mechanisms in all of the main components of the thermal power plant. The use of internal combustion engines such as diesel engine in power generation is further studied. The aim of this research is to provide a description of the thermal power generation methods in an easily digestible form, and to conduct a comparison between them with a particular focus on the thermal efficiency, power range, and the type of fuel.
\end{abstract}

\section{INTRODUCTION}

Steam is the prime mover of thermal power plants. The water comes from an external source and the passes through a chemical treatment unit. Chemicals are added to purify the water and to avoid corrosion and chemical deposition in the plant pipes. The water is heated in the boiler and superheater unit until it becomes a superheated steam. This steam, due to the pressure difference, spins the turbine driving the power generator.

The steam is then condensed in the condenser-cooling tower unit and cycles back in the plant. Using different fuel source results in a different overall performance of the plant. The most common fuels used are coal and kerosene.

In addition to electrical power generation, thermal power plants are utilized in different industries for the purpose of heating, especially in the cold environments. However, people are becoming more concern about climate change and the excessive pollution and smoke produced from thermal power plants.

The amount of $\mathrm{CO} 2$ emissions from the burned fuel plays a vital role in the quality or air and temperature due to global warming [1-3].

\section{THERMAL POWER PLANTS COMPONENTS}

Thermal power plants consist of many important components. Optimizing the operation of every single component would result in a huge improvement of the entire power plant. As illustrated in Fig.1, these components include Turbine units, condensers unit, cooling tower units, pumps, chemical treatment units, boiler and superheater units, generator and transformers unit, conveyors, electrostatic precipitators, and pulverizers. More details and the role of these components is explained in the next section.

\section{Condenser:}

Condenser is a heat exchanger device (shell and tube) that cools the extracted steam from both high pressure and lower pressure turbines using the water from the cooling tower unit. Condensers are typically placed at the exit of the turbine units. The pressure remains the same in the condensing process while the form of steam changes from gas to liquid.

Smoke stack:

The role of smoke stacks is to ventilate the boiler chamber and to push the exhaust gas out of the unit.

Coal conveyor:

This belt unit is to facilitate the delivery of the fuel tanks and coal to the furnace. 


\section{International Journal of Engineering Applied Sciences and Technology, 2020 \\ Vol. 5, Issue 6, ISSN No. 2455-2143, Pages 111-115 \\ Published Online October 2020 in IJEAST (http://www.ijeast.com)}

\section{Pulveriser:}

This is used to process the coal fuel before entering the boiler unit.

\section{Boiler:}

This is also a heat exchanger unit. The fuel is burned, and the water passes through steel pipes. The boiler heats up the water to a certain temperature before entering the superheater unit. Some plants use multiple boiler units which is called regenerative power plants.

\section{Electrostatic precipitator:}

This is basically an advanced dust removal. It creates an electric field whereby the exhaust chemical particles are collected.

\section{Generator:}

The generator is the main source of the output electrical power of the plant. It is an electromechanical equipment that converts the kinetic energy of the turbine blades into power.

\section{Economizer:}

This is a second heating stage. The economizer simply utilizes the heat of the exhaust gases for a second heating round.

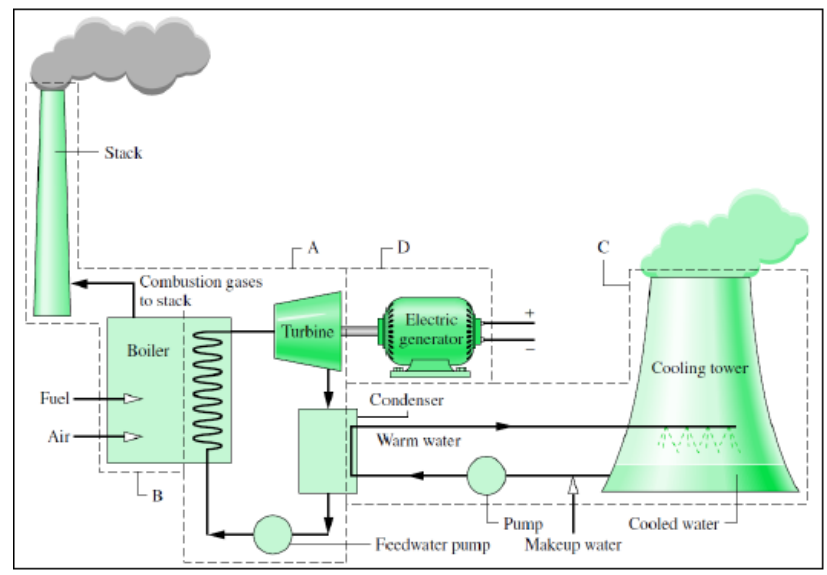

Fig.1: Power plant components

\section{Cooling Towers:}

A cooling tower is a heat exchanger device that supplies the conder unit with a relatively cold water and absorbs the heat of the steam. Cooling towers are used to reject heat from water to the atmosphere air by means of heat and mass transfer. Cooling towers consist of exhaust fans, fins, frame, fills, cold water basin and water pipes.
There are different types of cooling towers such as natural draft cooling towers and mechanical draft cooling towers. The performance of the cooling tower is governing by the ambient wet bulb temperature, air pressure, and most importantly water quality. The role of cooling towers is shown in Fig.2.

The water is sprayed by spray nozzles and splash bars. The fan circulates the air in the case of mechanical draft cooling towers. Whereas in natural draft cooling towers, air circulation is done naturally by wind currents.

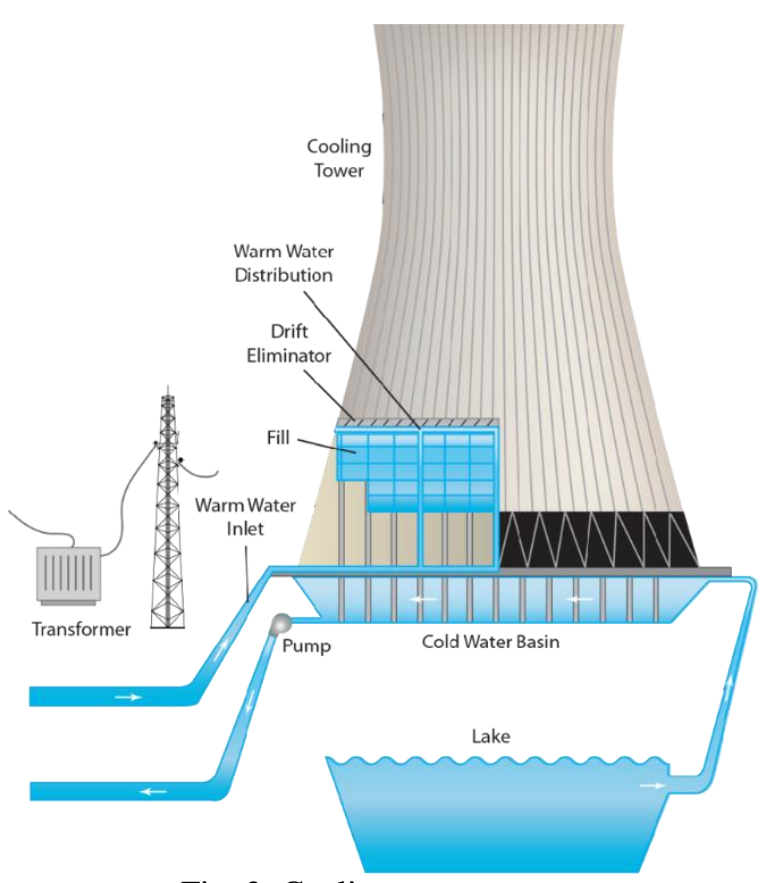

Fig..2: Cooling tower system

\section{BASIC CONCEPTS IN THERMAL POWER GENERATION}

Thermal power plant generally is based on ideal Rankine cycle concept. If the working fluid passes through the various components of the simple vapor power cycle without irreversibility, frictional pressure drops would be absent from the boiler and condenser, and the working fluid would flow through these components at constant pressure [4]. Also, in the absence of irreversibility and heat transfer with the surroundings, the processes through the turbine and pump would be isentropic. 


\section{International Journal of Engineering Applied Sciences and Technology, 2020 \\ Vol. 5, Issue 6, ISSN No. 2455-2143, Pages 111-115 \\ Published Online October 2020 in IJEAST (http://www.ijeast.com)}

A cycle adhering to these idealizations is the ideal Rankine cycle shown in Fig. 3.

We see that the working fluid undergoes the following series of internally reversible processes:

Process 1-2: Isentropic compression in a pump.

Process 2-3: Constant pressure heat addition in a boiler.

Process 3-4: Isentropic expansion in a turbine.

Process 4-1: Constant pressure heat rejection in a condenser.

Water enters the pump at state 1 as saturated liquid and is compressed isentropically to the operating pressure of the boiler. The water temperature increases somewhat during this isentropic compression process due to a slight decrease in the specific volume of water. The vertical distance between states 1 and 2 on the T-s diagram is greatly exaggerated for clarity.

Water enters the boiler as a compressed liquid at state 2 and leaves as a superheated vapor at state 3 . The boiler is basically a large heat exchanger where the heat originating from combustion gases, nuclear reactors, or other sources is transferred to the water essentially at constant pressure. The boiler, together with the section where the steam is superheated (the superheater), is often called the steam generator.

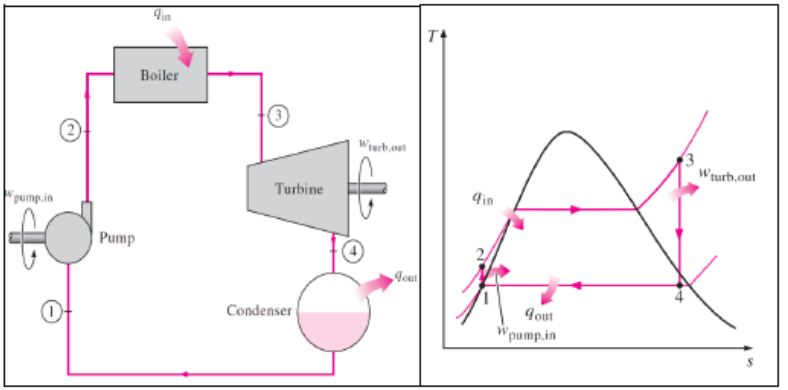

Fig.3: Ideal Rankine cycle diagram

The superheated vapor at state 3 enters the turbine, where it expands isentropically and produces work by rotating the shaft connected to an electric generator. The pressure and the temperature of steam drop during this process to the values at state 4 , where steam enters the condenser. At this state, steam is usually a saturated liquid-vapor mixture with a high quality. Steam is condensed at constant pressure in the condenser, which is basically a large heat exchanger, by rejecting heat to a cooling medium such as a lake, a river, or the atmosphere. Steam leaves the condenser as saturated liquid and enters the pump, completing the cycle [4]. In areas where water is precious, the power plants are cooled by air instead of water. This method of cooling, which is also used in car engines, is called dry cooling. Several power plants in the world, including some in the United States, use dry cooling to conserve water.

\section{Diesel power plants}

The diesel generator [6] has been seen to be the choice of many of the larger companies as it is well suited for industrial use (Fig.4). A major discouraging factor for its use in terms of the retail market has been the fact that it can be rather noisy, but this has been reduced greatly from the first diesel generators and is now almost comparable to the gasoline generators. These generators also offer other perks such as increase fuel economy and reduced maintenance costs which can explain their popularity in industrial applications [5].

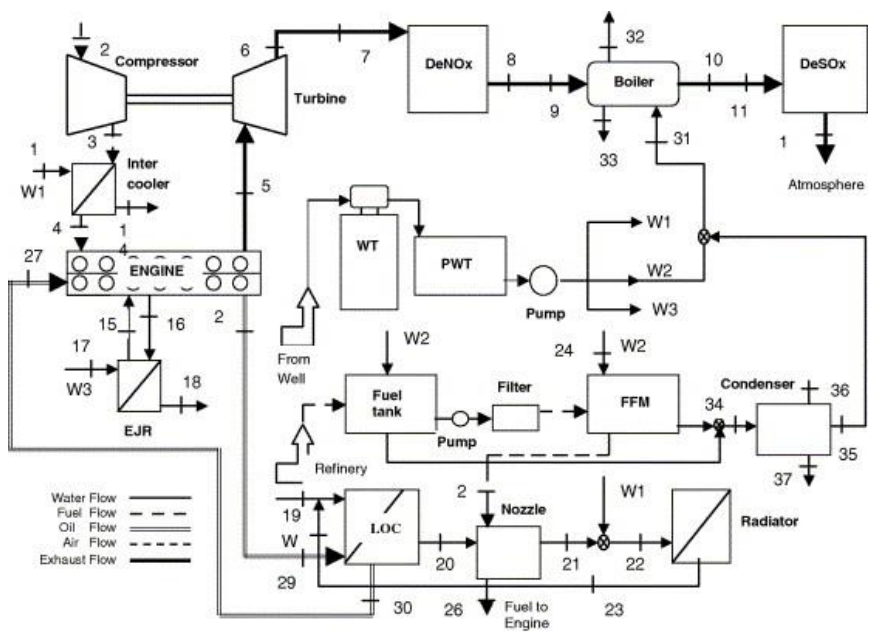

Fig.4: schematic of the diesel power plant [6]

The power generation applications of piston engines are enormously varied. Small units can be used for standby power or for combined heat, and power in 60 homes and offices. Larger standby units are often used in situations where a continuous supply of power is critical; in hospitals or to support highly sensitive computer installations such as air traffic control [4].

Many commercial and industrial facilities use medium-sized piston engine- based combined heat and power units for base-load power generation. Large engines, meanwhile, can be used for baseload, gridconnected power generation while smaller units form one of the main sources of base load power to isolated communities with no access to an electricity grid.

Piston engines used for power generation are almost exclusively derived from engines designed for motive applications. Smaller units are normally based on car 


\section{International Journal of Engineering Applied Sciences and Technology, 2020 \\ Vol. 5, Issue 6, ISSN No. 2455-2143, Pages 111-115 \\ Published Online October 2020 in IJEAST (http://www.ijeast.com)}

or truck engines while the larger engines are based on locomotive or marine engines. Performance of these engines varies. Smaller engines are usually cheap because they are mass produced but they have relatively low efficiencies and short lives. Larger engines tend to be more expensive, but they will operate for much longer [7-9].

The packaged combination of a diesel engine, a generator, and various ancillary devices such as base, canopy, sound attenuation, control systems, circuit breakers, jacket water heaters, starting systems etc, is referred to as a generating set or a gen set for short.

While the larger industrial generators can range from 8 to $30 \mathrm{kVA}$ for homes, small shops \& offices up to 2,000 kVA used for large office complexes, factories. A 2,000 kVA set can be housed in a 40ft ISO container and be fully packaged and portable. Sizes up to about $5 \mathrm{MW}$ are used for small power stations and these may use from one to 20 units [4]. In these larger sizes the engine and generator are brought to site separately and assembled along with ancillary equipment.

Diesel generators, sometimes as small as $250 \mathrm{kVA}$ are widely used not only for emergency power, but also many have a secondary function of feeding power to utility grids either during peak periods, or periods when there is a shortage of large power generators.

Ships often also employ diesel generators, sometimes not only to provide auxiliary power for lights, fans, and winches, etc. but also indirectly for main propulsion as explained in [10].

With electric propulsion (Fig.5) the generators can be placed in a convenient position, to allow more cargo to be carried. Electric drives for ships were developed prior to WW I. Electric drives were specified in many warships built during WW II because manufacturing capacity for large reduction gears was in short supply, compared to capacity for manufacture of electrical equipment. Such a diesel-electric arrangement is also used in some very large land vehicles.

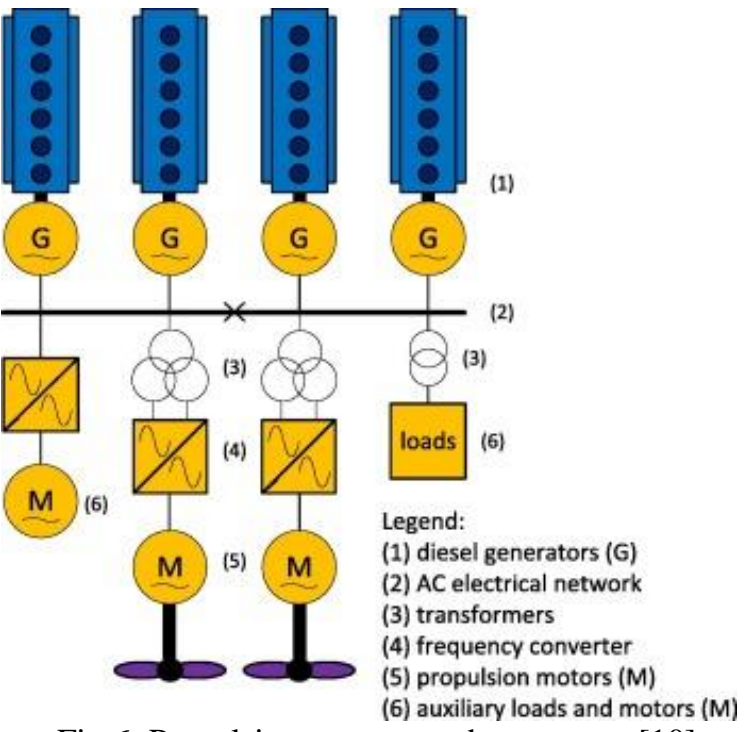

Fig.6: Propulsions system and generators [10]

Generating sets are selected based on the load they are intended to supply power for, taking into account the type of load, i.e. emergency or for continuous power, and the size of the load, and size of any motors to be started which is normally the critical parameter [4]. Internal combustion engines of many types are used for stationary power generation in a wide variety of services: central stations, oil fields, pipelines, sewage disposal, and commercial, institutional, and military bases.

As shown in Fig. 6, the compression ignition engines serve in steam stations to supply auxiliary power and in some industrial plants and institutional as emergency stand-by sources of energy in the event of main power-supply failure. In some smaller systems I.C engines work with steam units to supply the peakload demands on the plant [11]. 


\section{International Journal of Engineering Applied Sciences and Technology, 2020 \\ Vol. 5, Issue 6, ISSN No. 2455-2143, Pages 111-115 \\ Published Online October 2020 in IJEAST (http://www.ijeast.com)}
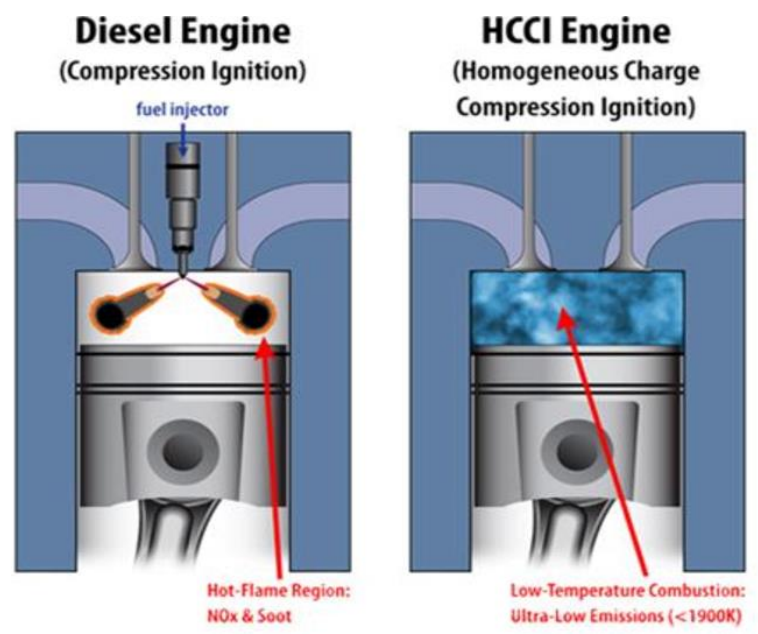

Fig.6: Diesel Engine and Compression Engine [11]

\section{SUMMARY AND CONCLUSION}

Part of the most important concepts in thermal power generation have been investigated in this review article. Furthermore, the main components of thermal power plants and their role in the operation of the power plant were investigated. The fundamentals of Rankine cycle, thermodynamics and heat transfer laws are critical in thermal power generation. Therefore, a good part of this review article has been dedicated to Rankine cycles, heat transfer mechanisms in the main components of the thermal power plant. The role of internal combustion engines such as diesel engine was further studied. The aim of this research was to suggest a description of these power generation methods in an easily understandable form, and to make a comparison between them especially the thermal efficiency, power range, and the type of fuel.

\section{REFERENCES}

1. Mittal, M. L., Sharma, C., \& Singh, R. (2012, August). Estimates of emissions from coal fired thermal power plants in India. In 2012 International emission inventory conference (pp. 13-16).

2. Giuliano, S., Buck, R., \& Eguiguren, S. (2011). Analysis of solar-thermal power plants with thermal energy storage and solar-hybrid operation strategy. Journal of Solar Energy Engineering, 133(3).

3. Nazari, S., Shahhoseini, O., Sohrabi-Kashani, A., Davari, S., Paydar, R., \& Delavar-Moghadam, Z. (2010). Experimental determination and analysis of $\mathrm{CO} 2, \mathrm{SO} 2$ and NOx emission factors in Iran's thermal power plants. Energy, 35(7), 2992-2998.
4. Mahmoud, D., Eesa, M.(2010). Comparison between Mechanical Power Generation Plants (M.Sc. Thesis)

5. Vincent, E. T. (1961). U.S. Patent No. 3,007,302. Washington, DC: U.S. Patent and Trademark Office.

6. Kanog`lu, M., Işıı, S. K., \& Abuşog`lu, A. (2005). Performance characteristics of a diesel engine power plant. Energy Conversion and Management, 46(11-12), 1692-1702.

7. Dzida, M. (2009). On the possible increasing of efficiency of ship power plant with the system combined of marine diesel engine, gas turbine and steam turbine, at the main engine-steam turbine mode of cooperation. Polish Maritime Research, 16(1), 47-52.

8. Solantausta, Y., Nylund, N. O., Westerholm, M., Koljonen, T., \& Oasmaa, A. (1993). Woodpyrolysis oil as fuel in a diesel-power plant. Bioresource Technology, 46(1-2), 177-188.

9. Buriakovskyi, S., Liubarskyi, B., Maslii, A., Pomazan, D., \& Tavrina, T. (2020). Research of a Hybrid Diesel Locomotive Power Plant Based on a Free-Piston Engine. Communications-Scientific letters of the University of Zilina, 22(3), 103-109.

10. Geertsma, R. D., Negenborn, R. R., Visser, K., \& Hopman, J. J. (2017).

Design and control of hybrid power and propulsion systems for smart ships: A review of developments. Applied Energy, 194, 30-54.

11. Graves, H., Le Pape, Y., Naus, D., Rashid, J., Saouma, V., Sheikh, A., \& Wall, J. (2014). Expanded material degradation assessment (EMDA), Volume 4: Aging of concrete. Technical Rep. NUREG/CR-7153, ORNL/TM-2011/545, United State Nuclear Regulatory Commission, Rockville, MD. 